\title{
The Implementation of a New Method of Student Assessment in a Pathogenic Bacteriology Laboratory Course
}

\author{
M. F. HITE* \\ Biology Department, University of North Carolina at Charlotte, Charlotte, North Carolina 28223
}

\begin{abstract}
A new case study method of assessment was developed to challenge advanced undergraduate biology majors interested in medical careers and allied health professions. This method is an alternative to traditional "unknown" identifications used in many microbiology laboratories. Students used various biochemical tests and selective media throughout the course to identify organisms cultured from their own bodies. In preparing a final assessment for the course, an assignment was developed to challenge the students to apply what they had learned in a medically relevant setting. Also of importance was the elimination of further biochemical testing by these students and prevention of contact with strict pathogens in this lab, due to budget and safety constraints, respectively. Each student was provided with a clinical specimen data record sheet and additional information about their "diseased patient”. Students used analytical skills and critical thinking, as well as knowledge gained throughout the semester, to logically deduce the causative agent of disease in the mock patients. Students were required to: (i) describe the steps in this logical deduction, (ii) provide a brief overview of the characteristics and virulence factors of the organism(s), (iii) investigate all disease(s) caused by the organism, (iv) describe symptomology of the patient in detail, and (v) investigate disease treatment and prevention methods. The final assignment involved library and Internet research and culminated in a written report, which further developed writing and communication skills. Detailed descriptions of and materials for this assignment are provided along with an overall evaluation of this method after implementation.
\end{abstract}

Educational overview. Over the past decade numerous sources have called for reforms in higher education. Arguably, one of the most comprehensive studies on the issue of reform in science and mathematics was undertaken by the Division of Undergraduate Education at the National Science Foundation. The findings and recommendations of this review group were published in the widely distributed report "Shaping the Future: New Expectations for Undergraduate Education in Science, Mathematics, Engineering, and Technology" (3). While all of the recommendations present challenges to faculty in higher education, two seem to fit well with microbiologists challenged to define and redesign laboratory curricula. These recommendations can be summarized as follows:

- Build inquiry, the process of science, and cutting edge research into every course.

- Devise and use pedagogy that develops skills for communication, teamwork, and critical thinking for each student.

Course information and background. The laboratory course in Pathogenic Bacteriology is offered to graduate students and senior biology majors who are typically preprofessional school students or are interested in pursuing an option in microbiology. The lecture portion of the course covers many of the most important bacterial pathogens (categorized by genus) and elaborates on virulence factors and means by which the organisms cause disease. The laboratory for this course requires that the students take samples from their own bodies and isolate normal flora from

*Corresponding author. Mailing address: 9201 University City Blvd., Biology Department, University of North Carolina at Charlotte, Charlotte, NC 28223. Phone: (704) 687-3422. E-mail: mfhite@email.uncc.edu. various genera using selective media, microscopy, and biochemical tests. Although this lab focuses on the flora of the skin, respiratory system, and intestinal tract, students also investigate soil and water samples for potential pathogens. Because it is unlikely that these students would be harboring or isolate many of the organisms they learn about in the lecture portion of the class, thorough details regarding isolation, characterization, and identification of pathogens are reviewed at the beginning of each section of the lab. This correlation attempts to reinforce that organisms from their normal flora (although most are nonpathogenic) can be cultured similarly to pathogenic organisms appearing in clinical settings.

Previously, the lab curriculum was mostly content-driven as opposed to goal-based, and the lab grades were solely based upon attendance and the laboratory notebook (1). Notebooks included detailed documentation of all samples, media, supplies, microscopy, and biochemical tests conducted throughout the semester. This documentation culminated in an identification of the normal flora from various areas of the students' bodies as well as organisms isolated from their soil and water samples. The notebooks were submitted at the end of the semester to evaluate each student's knowledge of the subject material. Students were given the option of turning in the notebook at mid-semester to identify any problems before the final evaluation of the notebook. Often, students who did not take advantage of this option received the lowest grades in the lab due to the critical evaluation and significance of these notebooks. However, since the notebook was merely a documentation of lab work, it was not necessarily a good indication of how much the student learned or retained during the semester and therefore was not very useful as a final assessment tool for this 
lab. Additionally, the students did not seem to easily relate the lab material to the lecture material, even though they were characterizing their normal flora from the same genera as the pathogens they were learning about in lecture. Moreover, grade determination and evaluation of these lab notebooks routinely proved highly subjective even though a variety of methods were in place to keep this from occurring (5).

Implementation of Case Study. After carefully examining the lab curriculum, the focus of the lab exercises was amended to make them more goal-oriented, and an additional method of assessment was used in this laboratory course. Taking into account that the lecture provides indepth genus descriptions and thorough information on pathogenesis and virulence factors, a set of criteria and goals was developed for the accompanying laboratory course. One goal was to have students develop and use problem-solving skills based on the large amount of information they had learned during the semester. Students were discouraged from memorizing media and tests used for specific organisms and encouraged to think critically and independently regarding the transmission, pathogenesis, and diagnosis of disease. Lastly, students were provided with a final task that would allow them to actively and creatively use knowledge and skills from the course to evaluate how well they had learned the material.

Individual case studies were used to achieve these goals. Case study analysis allowed students to link concepts of pathogenesis from the lecture to the organisms that were causing disease in the case studies. They found additional information on each genus by referring to their independent studies isolating normal flora. Examples of case studies in the literature were paramount to design and review the appropriateness of the case studies used in this class (2, 4, http:/ /ublib.buffalo.edu/libraries/projects/cases/aids.htm, http:// www.microbelibrary.org, http://www.asmusa.org/edusrc/ souvenir/index.html).

Our concerns now shifted to safety, budget, and time constraints. We realized that allowing the students to work with strict pathogens in the lab would be dangerous and costly; however, we wanted the stigma that comes with the "nasty" pathogens. We decided to substitute nonpathogenic organisms from our general microbiology laboratory stocks of the same Gram reaction, morphology, and arrangement for those that each case study described (Table 1). Our intention was not to replace the skills that result from handling strict pathogens but instead to provide a simple, exciting alternative for our students. Thorough safety training during the introduction of this lab allowed students to compare handling procedures between strict pathogens and nonpathogens throughout the semester. The case study "specimens" were supplied to the students using a disposable Culturette transport system (Becton Dickinson Microbiology Systems, Sparks, MD). Students were encouraged to use the same caution with these cultures as they would with any unknown isolates while performing Gram stains. Culturettes and slides were properly disposed once these stains were completed. This eliminated the need for and expense of ordering strains of strict pathogens. Moreover, this kept us at biohazard class 2 , adhering to university safety regulations. Yet, students retained the impression that they were working with realistic clinical samples. Obviously, these "imposter" cultures would not provide accurate biochemical data if tested, so this eliminated the possibility and expense of additional media for this assignment. To replace this otherwise pertinent part of the project, we created Clinical Specimen Data Records for each case (http://www.bioweb.uncc.edu/faculty/ hite). These data sheets incorporated accurate and relevant biochemical test results, any significant culture parameters for the specimen, and isolation information. In addition, a brief patient history was included on this sheet. Students were asked to brainstorm all possible causes explaining their patient's symptoms before performing a Gram stain. We intended to leave the students with many possible causative agents at this point in the assignment. We felt this helped to link the lecture class to the lab by requiring students to draw upon knowledge gained from lecture to form a list of all organisms with similar symptomology. Upon accurately finding the Gram reaction and morphology, they could narrow their search to a few particular organisms and use the biochemical information we provided to identify the most likely agent of disease in their patient.

Instructions for this assignment challenged the students to identify the organism causing the disease using the materials and supplies provided (http://www.bioweb.uncc.edu/ faculty/hite). Students were also notified of the formal report they would write on their case and the sections that needed to be included. These sections included but were not limited to: background, review of symptoms, diagnosis, treatment, prevention, and additional information. Finally, the students had to logically explain how they discovered the identity of the organism causing disease in their particular patient's case. We requested that this be a step-by-step dialogue applying the information we supplied regarding media, culture conditions, and biochemical tests to deduce a logical identity. Although instructions were detailed, we gave students freedom within each of these categories so as not to impose limitations. We guided them to use important resources already at their disposal, such as the lab manual, Bergey's Manuals (Systematic and Determinative), and lecture notes and texts. We also made it mandatory for the students to seek library resources for the report. They were instructed to use at least two peer-reviewed, scientific journals and one reliable Internet source.

To evaluate these reports objectively, a grading sheet was designed to define key concepts required in each report (http:/ /www.bioweb.uncc.edu/faculty/hite). The rubric was initially created to demonstrate the components a thorough report should contain and to make students aware of concepts they may have omitted. In addition, it allowed us to illustrate to the student which parts of each individual assignment had been done correctly (credits) and which parts were deficient (deductions). On the grading sheet we informed the student whether the correct diagnosis was made; however, we also 
TABLE 1. Cultures substituted for pathogens

\begin{tabular}{|c|c|c|c|}
\hline Case organism & $\begin{array}{l}\text { Gram reaction } \\
\text { and morphology }\end{array}$ & Diagnosis of case study & Actual organism used \\
\hline Corynebacterium diphtheriae & $\mathrm{G}^{+}$, irregular rod & diphtheria & C. xerosis \\
\hline Neisseria gonorrhea & G-, соссі & gonorrhea & N. sicca or N. subflava \\
\hline Neisseria meningiditis & G-, cocci & meningitis & N. sicca or N. subflava \\
\hline $\begin{array}{l}\text { Staphylococcus aureus } \\
\text { (coagulase negative) }\end{array}$ & $\mathrm{G}^{+}$, сосci & $\begin{array}{l}\text { absess, } \text { TSS, }^{a} \\
\text { osteomyelitis, pneumonia }\end{array}$ & S. aureus (coagulase positive) \\
\hline Streptococcus pneumoniae & $\mathrm{G}^{+}$, соссі & pneumonia and meningitis & S. mitis, S. mutans, or S. lactis \\
\hline Streptococcus pyogenes & $\mathrm{G}^{+}$, сосci & $\begin{array}{l}\text { pharyngitis, scarlet fever, } \\
\text { rheumatic fever }\end{array}$ & S. mitis, S. mutans, or S. lactis \\
\hline Clostridium perfringens & $\mathrm{G}+$, rod & $\begin{array}{l}\text { gas gangrene wound } \\
\text { infection }\end{array}$ & $\begin{array}{l}\text { Any Bacillus species which forms } \\
\text { spores readily }\end{array}$ \\
\hline Shigella dysenteriae & G-, rod & shigellosis & Salmonella typhimurium \\
\hline Salmonella enteriditis & G-, rod & salmonellosis & S. typhimurium \\
\hline $\begin{array}{l}\text { Escherichia coli } \\
\left(0157: \mathrm{H7}, \mathrm{EHEC},^{b}\right)\end{array}$ & G-, rod & $\begin{array}{l}\text { EHEC gastroenteritis } \\
\text { or colitis }\end{array}$ & E. coli (any nonvirulent strain) \\
\hline Escherichia coli (UPEC ${ }^{c}$ ) & G-, rod & $\begin{array}{l}\text { UPEC uriniary tract } \\
\text { infection }\end{array}$ & E. coli (any nonvirulent strain) \\
\hline
\end{tabular}
${ }^{a}$ Toxic Shock Syndrome
${ }^{b}$ enterohemorrhagic Escherichia coli
${ }^{c}$ uropathogenic Escherichia coli

included a section that allowed us to provide the student with information as to how their grade was derived. For example, on the grading sheet we noted whether the assignment was written at the appropriate level and with enough details. We made sure to include comments in this section showing the student exactly where the problems were in their assignment. We also noted if a student had put in extra creative efforts and gave them points back for this section if it was warranted. In general, students seemed pleased to receive this type of feedback as to how their scores were calculated and were affable regarding suggestions for improvement (http:// www.bioweb.uncc.edu/faculty/hite).

Thus far we have noted that the students enjoyed playing the role of the investigator and were ambitious to "prove" the causative agent of disease. They also became possessive and well informed about their patients. Students commented positively on the real-life application of this assignment. They also viewed this as a unique and profitable experience. Some noted that assuming the role of the physician or investigator helped them realize the relevance of clinical microbiology to various allied health fields. Additionally, we noticed that students who had not been extroverted during the semester now had confidence in their abilities and excelled at this assignment. Based on course evaluations, students benefited from this additional type of assessment and had a positive experience from the lab (http:// www.bioweb.uncc.edu/faculty/hite).

However, some problems have emerged. Some students procured very specific articles (as peer-reviewed journal sources) for which they could find no relevance to their final report. Although the journal fulfilled the source needed, the article did not contribute to the content of the paper. Unfortunately, a few students also had problems obtaining adequate mandatory resources required for this assignment. Their prin- ciple problem was deciphering which Internet sites were reliable for a formal class report and which were not. Independent students had no problem getting started, finding resources, or assimilating information; however, students who often need or expect "cookbook” protocols may become discouraged quickly. This leads us to believe that despite our efforts, some students will still be overwhelmed by this type of assignment and may require some extra instructional support. Yet, this type of concern has been noted by others using problem-based learning techniques (6).

In response to some of the students' suggestions, we have entertained the idea of not distributing cases randomly as described here, but allowing the students to read all cases and choose which one they like best. As these cases evolve, we will most likely add detail to the instructions for sources needed for this assignment or have the students bring in their articles for review before the assignment is due. Lastly, we will start this assignment earlier so that: (i) we can return the projects to the students with comments for discussion, and (ii) we can allow the students the option of reworking a deficiency in their final report for a higher grade.

\section{ADDITIONAL APPLICATIONS}

This method was developed to fit the needs of our pathogenic bacteriology laboratory course for biology majors. It is likely that modifications will be needed for it to become useful by others. As described in this paper, this method has been used successfully in labs ranging from 10 to 20 students. To accommodate higher enrollments, students could be paired or assigned to teams to decipher the organism causing disease. An example of such an adaptation, for those with larger lab enrollments or multiple lab sections (over 80 students), is the method we use to accommodate 
our allied health service course. Briefly, students are grouped into teams of two or three and given a slightly easier version of this assignment. They are given a Culturette inoculated with a nonpathogen that is able to cause opportunistic or nosocomial infections along with a patient history sheet. Their task is to culture the organism and do simple biochemical tests to decipher its identity. For this group, we include a modified table from the Bergey's Manual of Determinative Bacteriology to limit the possibilities and the biochemical tests needed. Changes regarding the final assignment should also be considered. We have envisioned that as this method evolves, final projects will also include verbal presentations with visual aids (possible with pairs or groups). This will allow the students to teach one another about the diseases and organisms. It is our intention to share our uses of this method as a foundation for others. Further development of this method will be dependent upon the desired outcome for a particular group of students.

\section{REFERENCES}

1. Angelo, T. A., and K. P. Cross. 1993. Classroom assessment techniques. A handbook for college teachers (2nd ed.). JosseyBass Publishers, Inc., San Francisco, Calif.

2. Cornley, K. 1998. The use of case studies in an undergraduate biochemistry course. J. Chem. Educ. 75:475.

3. Division of Undergraduate Education at the National Science Foundation. 1996. Shaping the future: new expectations for undergraduate education in science, mathematics, engineering, and technology. National Science Foundation, Arlington, Va.

4. Gillian, P. H., D. S. Shapiro, M. L. Smiley. 1996. Cases in medical microbiology and infectious diseases, 2nd ed.. ASM Press, Washington D.C.

5. Tobias, S., and J. Raphael. 1997. The hidden curriculum part I. Plenum Press, New York, N.Y.

6. White, H. B., and L. Richlin (ed.). 1996. The learning issue matrix. Biochemical Educ. 24:41-43.

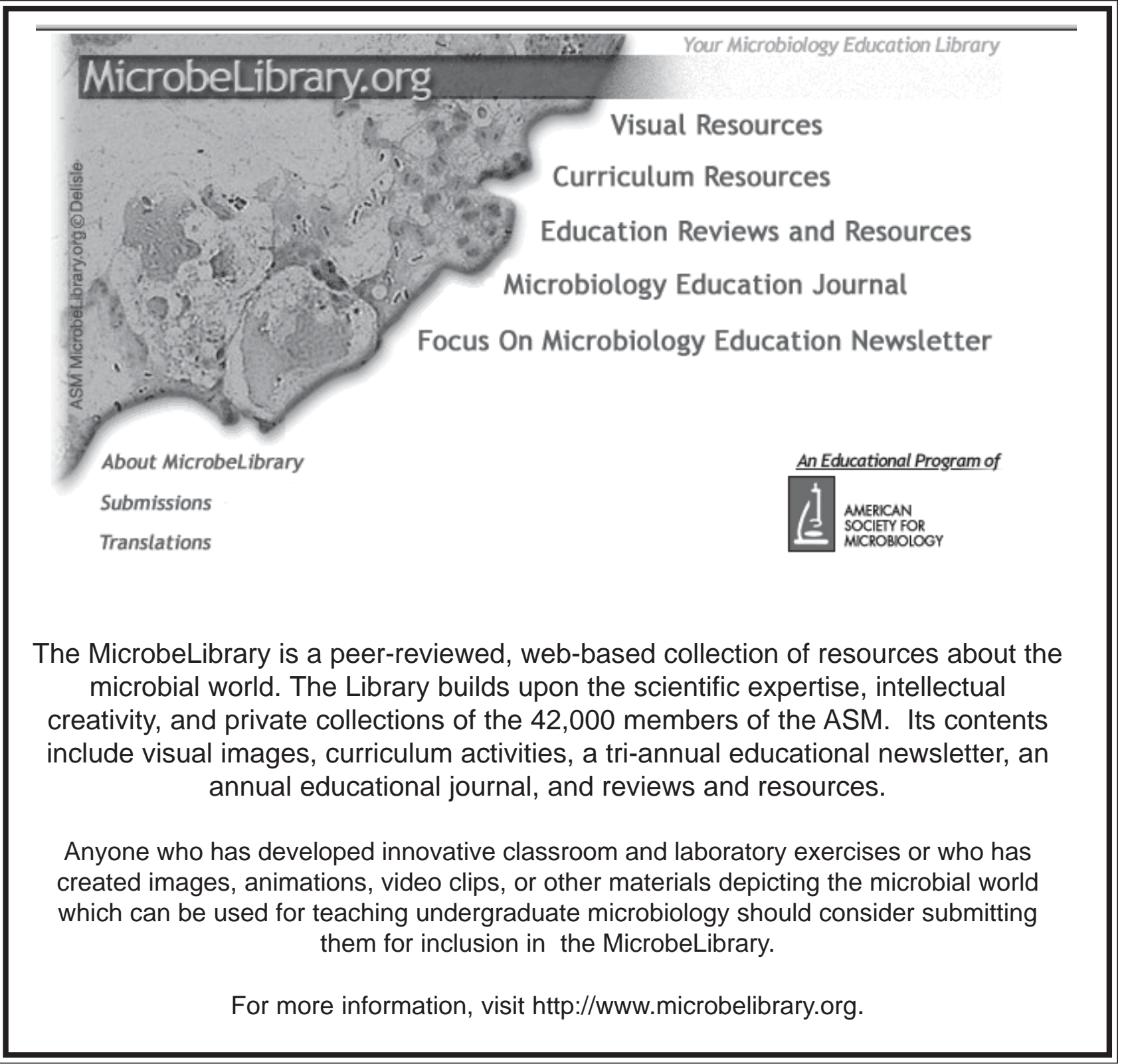

